\title{
An Electronic Learning Management System to train public health Medical Officers in Maternal and Child Health services in Sri Lanka
}

\author{
H.M.W.M. Karunarathne ${ }^{1 *}$, A.U. Jayathilake ${ }^{2}$, K. Kasthuriarachchi ${ }^{1}$, S.D.P.S. Senanayaka ${ }^{1}$, S.V.W.S. \\ Samarasinghe ${ }^{1}$, K.H.M. Kumarasinghe ${ }^{1}$, D.A. Dimal' ${ }^{1}$, M. Islam ${ }^{1}$, J.J. Hariyaram ${ }^{1}$, F.S. Mubarak ${ }^{2}$, S. Irfaan ${ }^{1}$, \\ L.A.C.N Liyanaarachchi \\ 1 Monitoring and Evaluation Unit, Family Health Bureau, Colombo, Sri Lanka \\ 2 Postgraduate Institute of Medicine, Colombo, Sri Lanka \\ *wedika@gmail.com \\ https://orcid.org/0000-0003-1365-4241
}

\begin{abstract}
Introduction: Reproductive, Maternal, New-born, Child, Adolescent and Youth Health (RMNCAYH) programme in Sri Lanka is an exemplary model in the region. Family Health Bureau (FHB) conducts numerous training programmes for different levels of public health staff involved in RMNCAYH services. Even though these training programmes are proven a success for many years, there are numerous challenges from both FHB and trainee's perspective due to resource limitation. The aim of this project was to assess the needs and to design \& develop an electronic learning management system to train public health medical officers in maternal and child health services.
\end{abstract}

Methods: The project contained two main components. The first component was a need assessment for a Learning Management System (LMS) for courses conducted by the Family Health Bureau among end-users. It was a cross-sectional descriptive study, using a self-administrated questionnaire among all Medical Officers of Health $(\mathrm{MOH})$, Additional Medical Officers of Health (AMOH) and Medical Officers of Maternal and Child Health (MO-MCH) distributed in electronic format. Email addresses were obtained from the official email database available at FHB. Associations were analysed using Kruskal-Wallis statistics - H. The second component was the designing and development of electronic LMS by customising free and open-source Moodle platform according to a custom-made development model. Pre-test conducted within the FHB among Medical Officers.

Results: Responses given to the questionnaire show that participants prefer courses with a shorter duration for conventional training programmes $(60.30 \%)$. The majority preferred blended training models over conventional methods (68.84\%). The preferred model (from online training, conventional, or blended training model) is significantly associated with previous participation in web-based training $(\mathrm{Ha}=12.04, \mathrm{DF}=1, \mathrm{P}=$ $0.001)$, knowledge of using internet/web surfing( $\mathrm{Ha}=10.73$, $\mathrm{DF}=1, \mathrm{P}=0.001)$, and how often participants using computer for office work $(\mathrm{Ha}=23.88, \mathrm{DF}=2, \mathrm{P}=0.000)$ respectively. $\mathrm{LMS}$ was developed by customising Moodle version 3.7.2, and the Theme selected was the 'Trending'. Alternations to the system were done according to the comments received. The final product was named as eBridge since the LSM is bridging the gap between the trainers and trainees.

Conclusions: Majority prefer blended training programmes in contrast to conventional programmes conducted by the FHB. Study variables related to computer and digital literacy of MOHs and AMOHs were significantly associated with the preferred method of training. The final product of the electronic learning management system to train Medical Officers of Health, Medical Officer of Maternal and Child Health was developed according to the needs. Post-implementation assessment needed to be carried on eBridge-LMS to assess the effectiveness and cost-benefit.

Keywords: eBridge, LMS, Moodle 